\title{
The inhibitory effect of nisin on Mycobacterium avium ssp. paratuberculosis and its effect on mycobacterial cell wall
}

\author{
Zeinab I. Ali, ${ }^{1}$ Adel M. Saudi, ${ }^{1}$ Ralph Albrecht, ${ }^{2}$ and Adel M. Talaat ${ }^{3 *}$ \\ ${ }^{1}$ Department of Food Hygiene and Control, Faculty of Veterinary Medicine, Cairo University, Giza, 11221, Egypt \\ ${ }^{2}$ Department of Animal Science, University of Wisconsin, Madison 53706 \\ ${ }^{3}$ Department of Pathobiological Sciences, University of Wisconsin, Madison 53706
}

\section{ABSTRACT}

Infection with Mycobacterium avium ssp. paratuberculosis (M. paratuberculosis) is a widespread problem in the United States and worldwide, and it constitutes a significant health problem for dairy animals with a potential effect on human health. Mycobacterium paratuberculosis is easily transmitted through consumption of contaminated milk; therefore, finding safe methods to reduce the mycobacterial load in milk and other dairy products is important to the dairy industry. The main objective of the current study was to investigate the effect of natural products, such as bacteriocins designated as "generally regarded as safe" (GRAS), on the survival of $M$. paratuberculosis in milk. Commercially synthesized bacteriocin (nisin) was used to examine its effect on the survival of laboratory and field isolates of M. paratuberculosis and in contaminated milk. Surprisingly, nisin had a higher minimum inhibitory concentration (MIC) against the laboratory strain ( $M$. paratuberculosis $\mathrm{K} 10$ ), at $500 \mathrm{U} / \mathrm{mL}$, than against field isolates (e.g., M. paratuberculosis 4B and JTC 1281), at $15 \mathrm{U} / \mathrm{mL}$. In milk, growth of $M$. paratuberculosis was inhibited after treatment with levels of nisin that are permissible in human food at $4^{\circ} \mathrm{C}$ and $37^{\circ} \mathrm{C}$. Using both fluorescent and scanning electron microscopy, we were able to identify defects in the bacterial cell walls of treated cultures. Our analysis indicated that nisin reduced membrane integrity by forming pores in the mycobacterial cell wall, thereby decreasing survival of M. paratuberculosis. Thus, nisin treatment of milk could be implemented as a control measure to reduce $M$. paratuberculosis secreted in milk from infected herds. Nisin could also be used to reduce $M$. paratuberculosis in colostrum given to calves from infected animals, improving biosecurity control in dairy herds affected by Johne's disease.

Received December 5, 2018

Accepted February 8, 2019.

*Corresponding author: Adel.Talaat@wisc.edu
Key words: Mycobacterium avium ssp. paratuberculosis, milk, nisin, Johne's disease

\section{INTRODUCTION}

Johne's disease or paratuberculosis is a chronic granulomatous infection of the intestines of wild and domestic ruminants caused by Mycobacterium avium ssp. paratuberculosis (M. paratuberculosis; Collins, 1997). Johne's disease can be transmitted from cows to calves through ingestion of $M$. paratuberculosis-infected colostrum or milk (Grant et al., 2002). Milk obtained under aseptic conditions from an asymptomatic $M$. paratuberculosis-infected cow could contain $<10 \mathrm{cfu} / 50$ $\mathrm{mL}$ of milk, whereas feces of the infected animal could contain $\geq 10^{8} \mathrm{cfu} / \mathrm{g}$ (Sweeney et al., 1992). Most likely, the major contamination risk of milk is through the indirect fecal route rather than via direct shedding of M. paratuberculosis into milk from infected animals (Nauta and van der Giessen, 1998). Although Johne's disease is not currently recognized as a zoonotic disease, a possible link exists between $M$. paratuberculosis and Crohn's disease in humans (Grant, 2005). Historically, M. paratuberculosis has been detected in both raw and pasteurized milk from cows, sheep, and goats, with isolation of the organism from several dairy products (Ikonomopoulos et al., 2005). Moreover, several laboratory pasteurization studies have reported that $M$. paratuberculosis can survive pasteurization of milk spiked with $\geq 10^{4} \mathrm{cfu} / \mathrm{mL} M$. paratuberculosis (Chiodini and Hermon-Taylor, 1993; Grant et al., 1996, 1998; Meylan et al., 1996). Reducing the milk load of M. paratuberculosis will reduce the risks to the health of both animals and humans. Currently, there is no approved protocol to eliminate $M$. paratuberculosis from contaminated milk, emphasizing the risk for more cycles of transmission to newborn calves and humans who consume contaminated milk and posing a significant public health concern (Lu et al., 2013). Although antibiotic use to reduce $M$. paratuberculosis in milk and dairy products is a potential control strategy, the excessive use of 
antibiotics and the potential of developing antibiotic resistance (Phillips et al., 2004) make this alternative impractical (WHO, 2001). Therefore, we focused our efforts on investigating whether bacteriocins, a group of effective antimicrobial peptides, could be used to help control M. paratuberculosis in milk and dairy products.

Bacteriocins are antimicrobial peptides that are active against several bacterial species, including Listeria monocytogenes, Staphylococcus aureus, Bacillus cereus, and other pathogens (Rilla et al., 2003, 2004). Nisin is a member of the class I bacteriocins also known as lantibiotics, which are ribosomally synthesized and posttranslationally modified antimicrobial peptides (Willey and van der Donk, 2007). Lantibiotics are produced in an inactive form and then activated by cleavage of the specific N-terminal leader peptide. These active lantibiotics have the ability to kill mainly gram-positive bacteria and some gram-negative bacteria (Chatterjee et al., 2005). Nisin is one of the most studied bacteriocins produced by lactic acid bacteria (Cotter et al., 2005), especially by strains of Lactococcus lactis ssp. lactis, and it is most frequently used to control both spoilage and pathogenic bacteria (Lubelski et al., 2008). In addition, nisin is the only bacteriocin that has been granted "generally regarded as safe" (GRAS) status by the US Food and Drug Administration and the World Health Organization (Balciunas et al., 2013). Previously, attempts to inactivate $M$. paratuberculosis in milk included the use of UV irradiation (Altic et al., 2007), high hydrostatic pressure with mild temperature (López-Pedemonte et al., 2006), and pulsed electric field (Rowan et al., 2001), none of which provided an efficient means for control. However, nisin has been found to be active against specific mycobacterial species such as Mycobacterium smegmatis and Mycobacterium bovis strains (Chung et al., 2000). More recently, nisin was considered a less potent agent against $M$. paratuberculosis, Mycobacterium kansasii, and Mycobacterium tuberculosis compared with lacticin 3147, another lantibiotic (Carroll et al., 2010). Another study (Kralik et al., 2018) reported no effect of nisin against M. paratuberculosis. To better examine the effect of nisin in controlling M. paratuberculosis in milk, we studied the survival M. paratuberculosis in laboratory cultures and in milk treated with different concentrations of nisin. Our analysis indicated that variable concentrations of nisin could reduce both laboratory and clinical isolates of M. paratuberculosis in culture and in milk. Specifically, nisin was able to introduce holes in $M$. paratuberculosis, leading to a "bulging" phenotype in treated cells when examined by scanning electron microscopy and illustrating the mechanism by which nisin acts on M. paratuberculosis.

\section{MATERIALS AND METHODS}

\section{Bacterial Cultures}

Four strains of $M$. paratuberculosis (K10, 4B, JTC 1281 , and JTC 1285) were tested in this study; K10 is a laboratory strain, 4B is a human isolate, JTC 1281 has been isolated from the oryx, and JTC 1285 has been isolated from goats (Hsu et al., 2011). All strains were grown in Middlebrook 7H9 broth (Difco Laboratories, Detroit, MI) supplemented with $0.05 \%$ (wt/vol) Tween 80 (Sigma Chemical Co., St. Louis, MO), 10\% (vol/vol) oleic acid albumin-dextrose-catalase (OADC) supplement (Difco Laboratories), and $2 \mu \mathrm{g} / \mathrm{mL}$ mycobactin J (Symbiotics Europe SAS, Lyon, France), pH 6.6. All cultures were incubated at $37^{\circ} \mathrm{C}$ with gentle shaking $(100 \mathrm{rpm})$ for 3 to $4 \mathrm{wk}$ until the optical density at 600 $\mathrm{nm}\left(\mathbf{O D}_{600}\right)$ was between 0.7 and 0.9 , as detailed previously (Wu et al., 2007). Lactococcus lactis LL108 is an indicator bacterial strain used as a control for nisin; it was propagated in de Man, Rogosa, and Sharpe broth medium and incubated at $30^{\circ} \mathrm{C}$ for $18 \mathrm{~h}$ at $150 \mathrm{rpm}$ (de Man et al., 1960).

\section{Broth Susceptibility Testing}

Commercially synthesized nisin was obtained from Sigma Chemical Co. A stock solution of $5,000 \mathrm{U} / \mathrm{mL}$ for nisin in $0.02 \mathrm{~N} \mathrm{HCl}$ was freshly prepared directly before each experiment. Different concentrations of nisin were prepared in Middlebrook $7 \mathrm{H} 9$ broth to obtain final concentrations of $500,250,125,62.5,31.25$, and $15.62 \mathrm{U} / \mathrm{mL}$ and then used to spike $100 \mu \mathrm{L}$ of the prepared bacterial suspension (approximately $1 \times 10^{6} \mathrm{cfu} /$ $\mathrm{mL}$ ). The tubes were incubated at $37^{\circ} \mathrm{C}$ and $\mathrm{OD}_{600}$ was monitored at 5 -d intervals for a period of $50 \mathrm{~d}$. Growth curves based on $\mathrm{OD}_{600}$ readings were plotted to compare the results with those cultures with no nisin added (negative control). The growth curves were repeated at least twice for the $4 \mathrm{M}$. paratuberculosis strains before statistical analysis. The lowest concentration of the bacteriocin in the test tubes with no visible or detectable bacterial growth (turbidity) was considered to represent the MIC (Wong et al., 2008).

\section{Microplate Alamar Blue Assay}

A colorimetric, microplate Alamar Blue assay (MABA) was used to estimate the MIC of nisin against tested M. paratuberculosis isolates (including field and laboratory strains). Twofold serial dilutions of nisin were prepared in a 96-well plate, with final concentrations of nisin ranging from 7.8 to $1,000 \mathrm{U} / \mathrm{mL}$, covering the range used for the broth susceptibility assay. One 
hundred microliters of $M$. paratuberculosis inoculum was added to each nisin-containing well. Wells containing inoculum only served as positive controls, whereas wells containing no bacterial cells served as negative controls. The plates were sealed and incubated at $37^{\circ} \mathrm{C}$ for 7 to $14 \mathrm{~d}$. Fifty microliters of a freshly prepared 1:1 mixture of $10 \times$ Alamar Blue (Accumed International, Westlake, $\mathrm{OH}$ ) reagent and $10 \%$ Tween 80 was added to one positive control. The plates were re-incubated at $37^{\circ} \mathrm{C}$ for $24 \mathrm{~h}$. When the positive well (inoculum only) turned pink, the reagent mixture was added to all wells in the microplate and the color of all wells was recorded. A blue color in the well was interpreted as no growth, and a pink color was scored as growth. The MIC was defined as the lowest bacteriocin concentration that prevented a color change from blue to pink (Franzblau et al., 1998).

\section{Nisin Treatment of M. paratuberculosis-Spiked Milk}

To test the antimycobacterial activity of nisin in milk and dairy products under different storage temperatures, samples of pasteurized skim cow milk $(50 \mathrm{~mL})$ were spiked with $2 M$. paratuberculosis strains (K10 and JTC 1285, representing laboratory and field isolates, respectively) to approximately $1.2 \times 10^{6} \mathrm{cfu} / \mathrm{mL}$. Different concentrations of nisin $(1000,500$, and $100 \mathrm{U} /$ $\mathrm{mL}$ ) were added to the spiked milk samples and incubated at 2 temperatures $\left(37^{\circ} \mathrm{C}\right.$ and $\left.4^{\circ} \mathrm{C}\right)$. The growth rate of each bacterial strain before and after treatment with nisin was obtained for each strain up to $20 \mathrm{~d}$ after nisin treatment at 5-d intervals (Gao et al., 2005). At each time point, culture aliquots were plated on Middlebrook 7H10 medium supplemented with OADC and mycobactin J, as detailed previously (Wu et al., 2007).

\section{Live/Dead Assay for Bacterial Viability}

The Live/Dead BacLight Bacterial Viability assay kit for fluorescence microscopy (Invitrogen/Thermo Fisher Scientific, Waltham, MA) was used to evaluate viability of $M$. paratuberculosis following nisin treatment using the manufacturer's directions. In this assay, a mixture of stains, SYTO 9 and propidium iodide (PI), was used to evaluate membrane integrity. The green-fluorescing SYTO 9 is able to enter all cells and is used to assess total cell counts, whereas red-fluorescing PI enters only cells with damaged cytoplasmic membranes. Three microliters of the stain mixture was added to bacterial cells previously treated with different concentrations of nisin $(1,000,500$, and $100 \mathrm{U} / \mathrm{mL})$ for $2 \mathrm{~h}$, and untreated cells were used as controls. The samples were incubated for $15 \mathrm{~min}$ in the dark at room temperature; then, 5 $\mu \mathrm{L}$ of each stained sample was trapped between a cov- erslip and glass slide to be viewed under a confocal fluorescence microscope (Olympus BX-51, Olympus, Tokyo, Japan), using a $60 \times$ objective sequentially with the fluorescence setting for fluorescein isothiocyanate (FITC; green/SYTO 9-positive cells) and PI (red/PIpositive cells) filters, followed by phase-contrast and bright-field settings. Images were acquired and analyzed using Olympus BX-51 software for quantification of live (green fluorescence) and dead (red fluorescence) cells.

\section{Scanning Electron Microscopy}

To investigate the effect of nisin on the membrane integrity of mycobacteria, we examined nisin-treated cultures using scanning electron microscopy (Biological and Biomaterials Preparation, Imaging and Characterization Facility, BBPIC, University of Wisconsin, Madison). Bacterial suspensions of $10^{8} \mathrm{cfu} / \mathrm{mL} M$. paratuberculosis $\mathrm{K} 10$ were mixed with nisin at the MIC $(500 \mathrm{U} / \mathrm{mL})$ and incubated at $37^{\circ} \mathrm{C}$ for $2 \mathrm{~h}$, Lactococcus lactis LL108 were incubated with nisin at the MIC $(10 \mathrm{U} / \mathrm{mL})$ as a control. After incubation, cells were centrifuged at $3,000 \times g$ for $10 \mathrm{~min}$, washed with PBS (pH 7.4) several times, and fixed with $2.5 \%$ glutaraldehyde in the same buffer overnight at $4^{\circ} \mathrm{C}$. After fixation, cells were washed 2 or 3 times in $0.1 M$ PBS (pH 7.4), dehydrated in series of graded ethanol solutions (30 to 100\%), and finally dried in a desiccator under vacuum. An automatic sputter coater (Polaron OMSC7640, Quorum Technologies, Ashford, UK) was used for coating the specimens with 20-nm gold particles. The samples were then viewed using scanning electron microscopy (EVO 40, Carl Zeiss, Germany) (Singh and Mukhopadhyay, 2011).

\section{Statistical Analysis}

Kolmogorov-Smirnov and Shapiro-Wilk tests for normality with $P$-value $\geq 0.005$; thus, all the data were in normal distribution. One-way ANOVA with repeated measures was followed by post hoc test (Tukey honestly significant difference test) for bacterial growth rate studies and 2-way ANOVA, Tukey's multiple comparison test when several growth kinetics were evaluated. The unpaired $t$-test with $P$-value $\leq 0.005$ was used for testing differences in dimensions of mycobacterial bacilli.

\section{RESULTS}

\section{Nisin Reduces the Viability of Mycobacteria}

To evaluate the bactericidal activity of nisin on different strains of $M$. paratuberculosis, we examined the 
growth of 4 strains of $M$. paratuberculosis over $50 \mathrm{~d}$ following treatment with varying concentrations of nisin. At different concentrations, nisin was found to inhibit the growth of all 4 strains of $M$. paratuberculosis tested in vitro during incubation at $37^{\circ} \mathrm{C}$ for up to $15 \mathrm{~d}$ after treatment, and the MIC for each strain was estimated (Figure 1). For some concentrations, the inhibitory effect continued up to $50 \mathrm{~d}$ after treatment. Interestingly, the tested strains had variable responses to nisin with different MIC recorded, ranging from $15.6 \mathrm{U} / \mathrm{mL}$ for all strains except the K10 strain, which had a MIC of 500 $\mathrm{U} / \mathrm{mL}$ at $15 \mathrm{~d}$. At $30 \mathrm{~d}$ after treatment, the MIC for K10 remained at $500 \mathrm{U} / \mathrm{mL}$, whereas that for JTC1285 was $62.5 \mathrm{U} / \mathrm{mL}$ and that for strains JTC1281 and 4B was $15.6 \mathrm{U} / \mathrm{mL}$ (Figure 1). Overall, strain K10 was the most nisin-resistant strain tested, suggesting that an adaptive response to nisin treatment could develop over time in M. paratuberculosis.
A

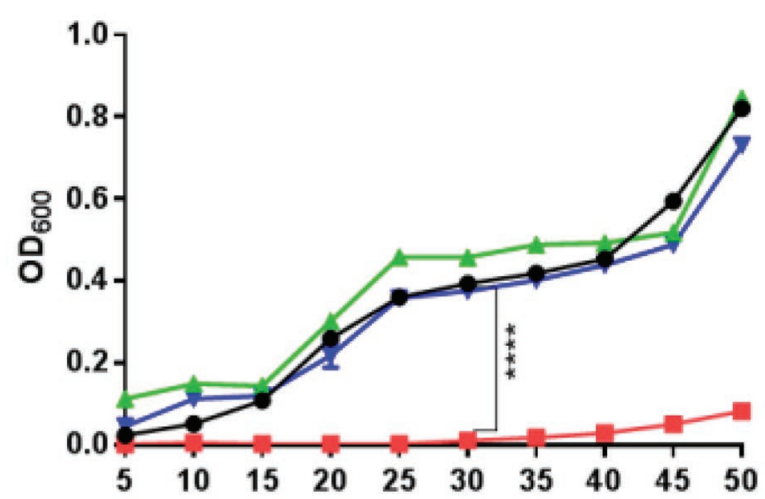

JTC 1285 OD600

B

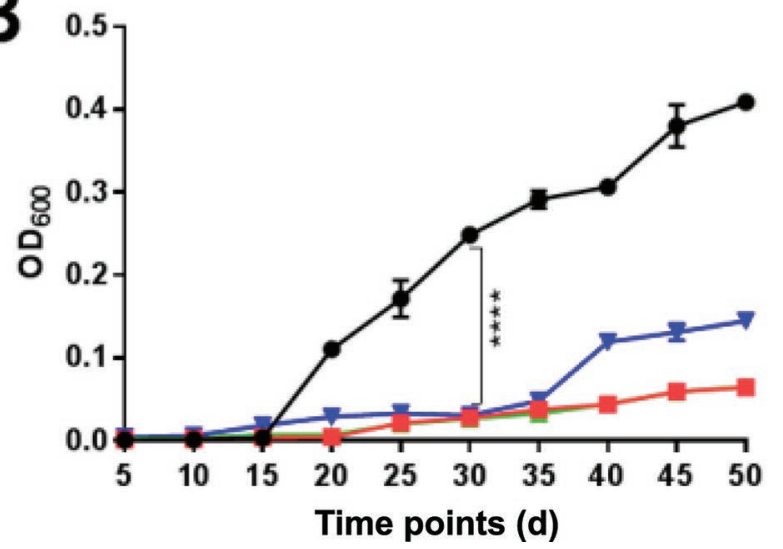

C

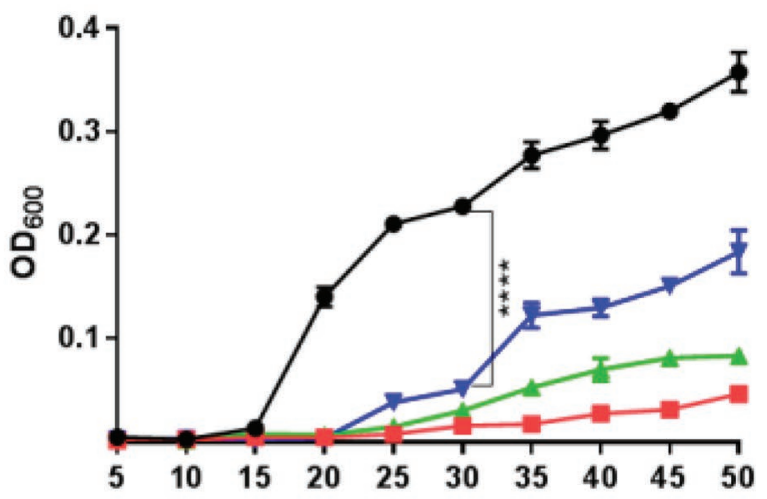

D

JTC1281 OD600

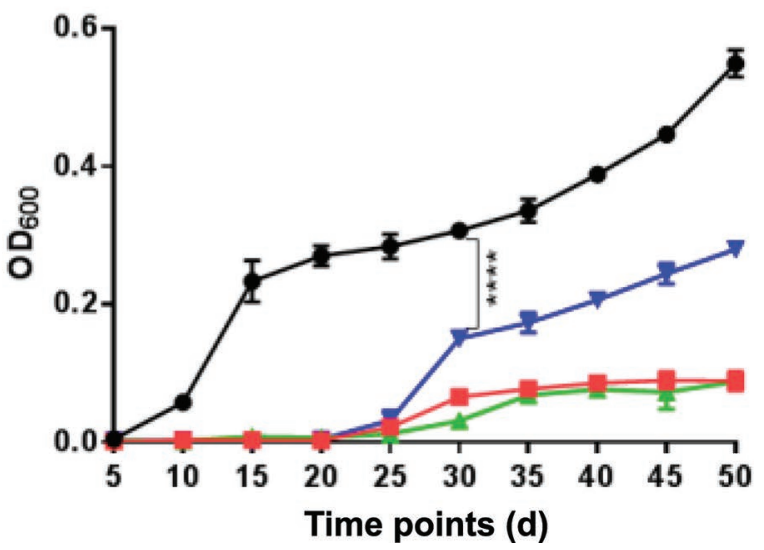

Figure 1. Growth kinetics of nisin-treated Mycobacterium avium ssp. paratuberculosis (MAP) cultures over time. Different strains of $M$.

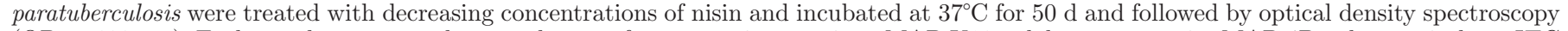
$(\mathrm{OD}$ at $600 \mathrm{~nm})$. Each panel represents the growth curve for one strain over time. MAP K10 = laboratory strain; MAP 4B = human isolate; JTC $1281=$ MAP strain isolated from oryx; JTC $1285=$ MAP strain isolated from goats. The difference between the control and treated cultures at d 30 was statistically significant $(* * * * P<0.0001)$. Error bars represent the standard error of the mean. 
Table 1. The antibacterial activity of nisin expressed as MIC (mean \pm $\mathrm{SD}, \mathrm{n}=3$ ) determined by the microplate Alamar blue assay

\begin{tabular}{lc}
\hline Bacterial strain $^{1}$ & Nisin MIC $(\mathrm{U} / \mathrm{mL})$ \\
\hline Lactococcus lactis II 108 & $10.0 \pm 0.0$ \\
MAP K10 & $500.0 \pm 0.0$ \\
MAP 4B & $15.0 \pm 0.0$ \\
JTC 1281 & $15.0 \pm 0.0$ \\
JTC 1285 & $62.5 \pm 0.0$
\end{tabular}

${ }^{1}$ MAP K10 = Mycobacterium avium $\mathrm{ssp}$. paratuberculosis (MAP) K10 (laboratory strain); MAP 4B = human isolate; JTC $1281=\mathrm{MAP}$ strain isolated from oryx; JTC $1285=$ MAP strain isolated from goats.

\section{Differential Effect of Nisin on Viability of Laboratory and Field Strains}

To confirm the differences observed in the sensitivity of different strains of $M$. paratuberculosis to nisin, we used MABA, which has more dynamic readings than can be obtained using a standard growth curve. The MABA test showed that all strains were inhibited by nisin at the end of the observation time at $14 \mathrm{~d}$ after treatment. The MIC for each strain tested are shown in Table 1. The M. paratuberculosis strains $4 \mathrm{~B}$ and JTC1281 were the most sensitive $(15 \mathrm{U} / \mathrm{mL})$, whereas M. paratuberculosis $\mathrm{K} 10$ was the most resistant (500 U/ $\mathrm{mL}$ ) and strain JTC1285 had an intermediate MIC at $62.5 \mathrm{U} / \mathrm{mL}$. Overall, results from the MABA confirmed results obtained from standard growth curves (Figure $1)$.

\section{Nisin Reduces M. paratuberculosis Survival in Milk}

Following inactivation of $M$. paratuberculosis in laboratory culture medium, we sought to examine its survival in a more complex but natural environment for M. paratuberculosis - milk. A field strain, JTC1285, was selected for these studies, as well as a laboratory strain, M. paratuberculosis K10, using pasteurized cow milk stored at $4^{\circ} \mathrm{C}$ and $37^{\circ} \mathrm{C}$. Because of the nature of milk and its normal turbidity, optical density measurement was not suitable so we used a standard bacterial plating method to examine cell viability and determine how many cells would die following nisin treatment. Three nisin concentrations $(100,500$, and 1,000 U/mL) were used; all of these concentrations are permissible in milk for human consumption (Delves-Broughton et al., 1996). As expected, the highest nisin concentration had a bactericidal effect on both strains at $4^{\circ} \mathrm{C}$ and $37^{\circ} \mathrm{C}$ (Figure 2). The lowest nisin concentration had only a bacteriostatic effect on both strains at both temperatures; that is, preventing their further growth compared with the no-treatment groups. Finally, the intermediate concentration $(500 \mathrm{U} / \mathrm{mL})$ of nisin had a bacteriostatic effect at $4^{\circ} \mathrm{C}$ but a bactericidal effect at $37^{\circ} \mathrm{C}$, which was more pronounced at $15 \mathrm{~d}$ after treatment $(P \leq 0.05)$. Generally, the presence of nisin in milk significantly reduced $(P<0.0001)$ the survival of M. paratuberculosis, especially at concentrations of 500 and $1,000 \mathrm{U} / \mathrm{mL}$.

\section{Nisin Affects Mycobacterial Membrane Integrity}

Because nisin treatment greatly affected the growth kinetics of $M$. paratuberculosis, we used the Live/Dead bacterial viability assay to examine the integrity of the mycobacterial cell wall. Compared with control samples, treatment with all concentrations of nisin triggered variable degrees of cell death (Figure 3), especially when $M$. paratuberculosis cultures were treated with $500 \mathrm{U} / \mathrm{mL}$ of nisin. As expected, the laboratory strain of $M$. paratuberculosis was least affected by nisin treatment, whereas the other strains were more sensitive.

An earlier report indicated that nisin works by creating pores in the target bacterial cell membranes, leading to cell death (Field et al., 2012). To test this hypothesis in the case of $M$. paratuberculosis, we used scanning electron microscopy to examine cultures treated with nisin. As expected, morphological changes were noted in M. paratuberculosis cells and in Lactococcus lactis LL 108, the nisin-sensitive strain used as a control. In addition to pore formation, analysis of the scanning electron micrographs of $M$. paratuberculosis cells revealed many structural changes in cells morphology (Figure 4). Treated M. paratuberculosis cells appeared to be bulged and shortened (i.e., wider and shorter) compared with untreated cells where they maintained normal appearance. Nisin-treated $M$. paratuberculosis had distorted contours and, in some cases, had noticeable membrane pores. Untreated $M$. paratuberculosis cells were long, smooth, and intact. Similar morphological changes were observed for the indicator bacteria, Lactococcus lactis LL108, exposed to nisin (Figure 4). Treated cells were shorter than controls with a significant difference observed for length $(P=0.0027$; Figure $5 \mathrm{~A})$ and width $(P<0.0001$; Figure 5B) of M. paratuberculosis bacilli before and after treatment with nisin. Overall, exposure of $M$. paratuberculosis to $500 \mathrm{U} / \mathrm{mL}$ nisin resulted in membrane damage, a distorted appearance, pore formation, and, in some cases, complete leakage of cell material.

\section{DISCUSSION}

Johne's disease is a chronic granulomatous enteritis of ruminants with great economic impact on the dairy industry (Berger et al., 2007). Infected animals can shed M. paratuberculosis in milk (Slana et al., 2008), and 
recent studies have shown that $M$. paratuberculosis can survive pasteurization (Grant et al., 2005) with potential risk to consumers. The public health concern stems from the potential ingestion of M. paratuberculosis from contaminated milk, with possible involvement in the development of Crohn's disease in a sub-population of individuals (Grant, 2005). Pasteurized milk replacer contaminated with $M$. paratuberculosis (Grant et al., 2017) can also constitute a potential source of infection for young calves. Previously, nisin has been shown to reduce the viability of many food-borne pathogens, including methicillin-resistant Staphylococcus aureus, vancomycin-resistant enterococci, and oxacillin-resistant gram-positive bacteria (Cotter et al., 2005). Nisin has a long history as an antimicrobial agent to control both spoilage and food-borne pathogens (SobrinoLópez and Martín-Belloso, 2008); however, the impact and mechanism of action of nisin on M. paratuberculosis is less understood. In this report, we focused our efforts on analyzing the antibacterial effect of nisin on $M$.

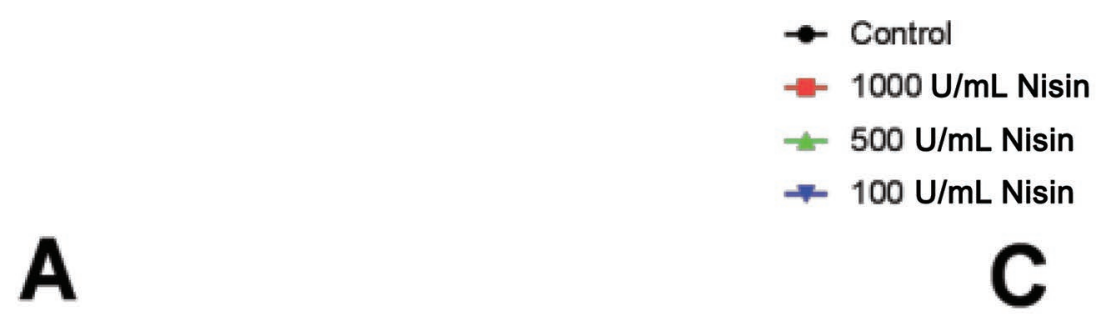

MAP K10 in milk at $37^{\circ} \mathrm{C}$

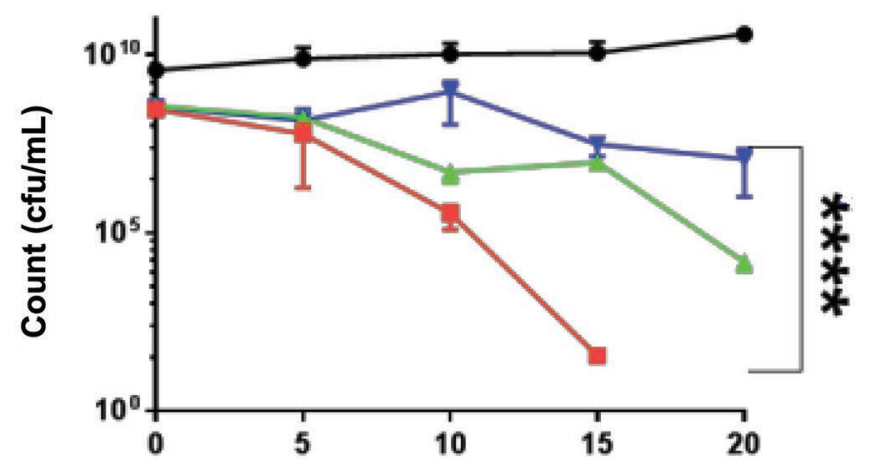

MAP K10 in milk at $4^{\circ} \mathrm{C}$

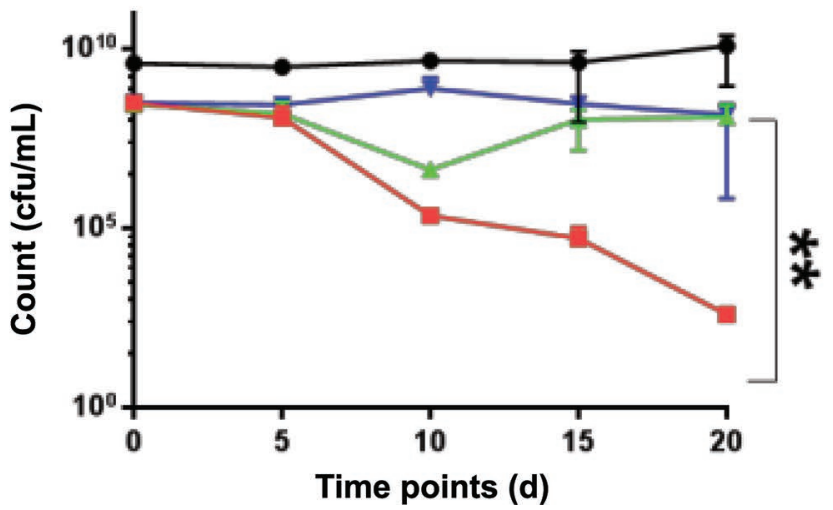

JTC 1285 in milk at $37^{\circ} \mathrm{C}$

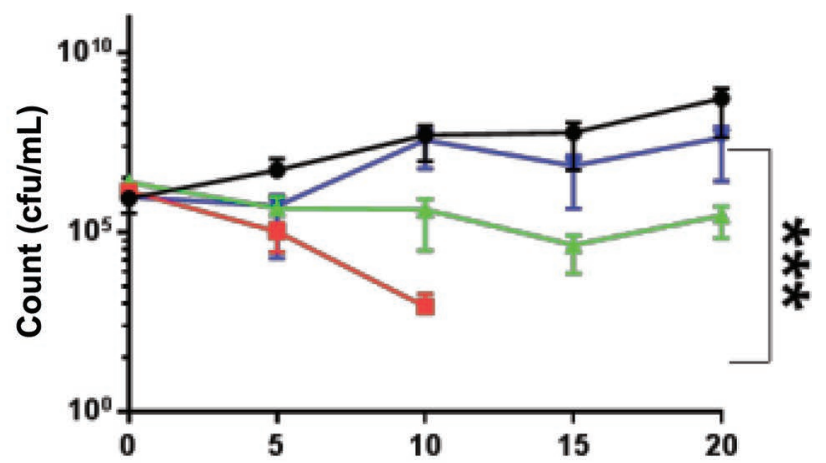

D

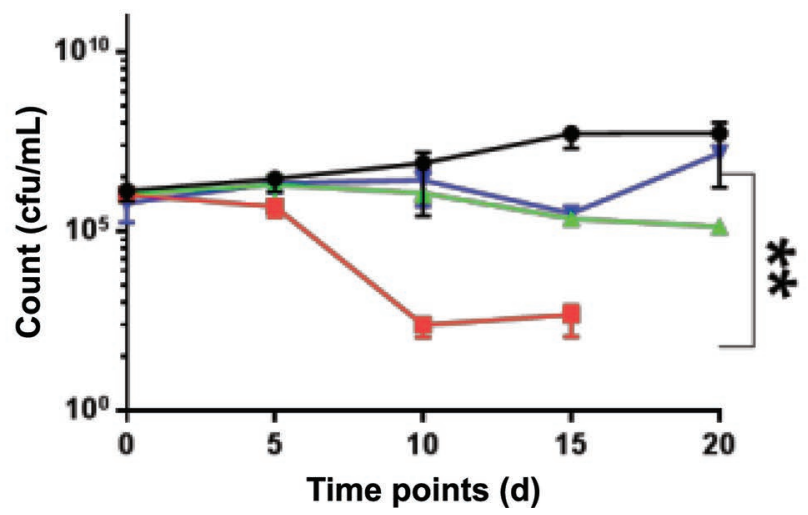

Figure 2. Growth kinetics of 2 Mycobacterium avium ssp. paratuberculosis strains (MAP K10 and JTC 1285) in milk following nisin treatment at 4 and $37^{\circ} \mathrm{C}$. Each panel represents the growth curve for one strain at one temperature. On d 20, the difference in mycobacterial survival between treatments was statistically significant: $* * * * P<0.0001,{ }^{* * *} P=0.0006,{ }^{*} P=0.0011$. Error bars represent the standard error of the mean. 


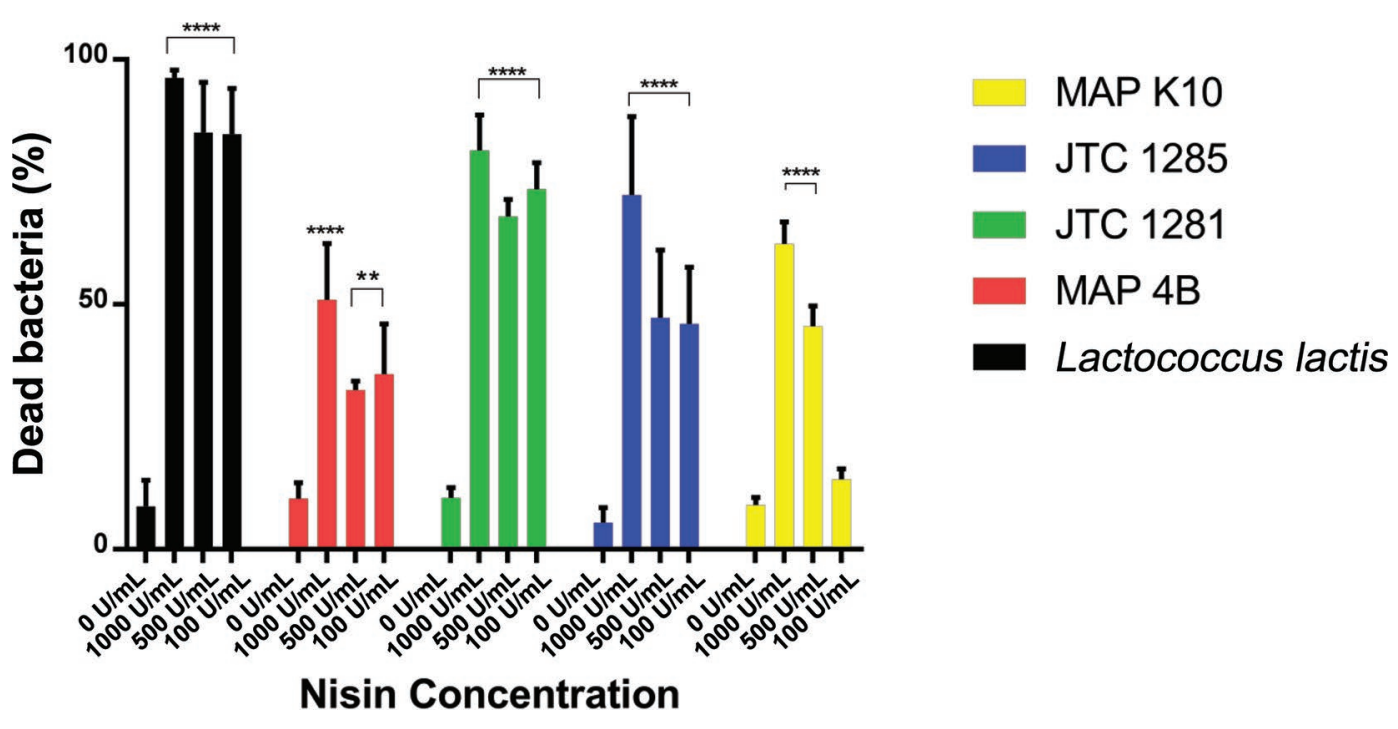

Figure 3. Percentage of dead mycobacteria following treatment with nisin at 0, 100, 500, or 1,000 U/mL. Different strains of Mycobacterium avium ssp. paratuberculosis (MAP) and the nisin indicator species Lactococcus lactis LL108 were treated with permissible levels of nisin and stained with a mixture of fluorescent dyes (propidium iodide and Syto 9) and examined under the fluorescent microscope to calculate the percentage of dead bacteria. MAP K10 = laboratory strain; MAP 4B = human isolate; JTC $1281=$ MAP strain isolated from oryx; JTC $1285=$ MAP strain isolated from goats. Asterisks indicate significant differences compared with the control treatment $(0 \mathrm{U} / \mathrm{mL}$ nisin $): * * * * P<0.0001$, ${ }^{* *} P=0.0037$. Error bars represent the standard error of the mean.

paratuberculosis and how nisin could be used to reduce the mycobacterial load in milk.

One of the promising findings of this study was that, except for the laboratory strain K10, M. paratuberculosis failed to grow at nisin concentrations $<100 \mathrm{U} / \mathrm{mL}$. An earlier study (Carroll et al., 2010) found that $60 \mathrm{U} /$ $\mathrm{mL}$ was below the $\mathrm{MIC}_{90}$ (the concentration inhibiting growth of $90 \%$ of isolates) for M. paratuberculosis and M. tuberculosis. The laboratory strain K10 could become tolerant to nisin using mechanisms similar to the adaptation of laboratory strains to stress conditions (Kralik et al., 2014). The different levels of sensitivity to nisin treatment by $M$. paratuberculosis observed in this study, even among field strains, further support the notion that genotyping variations among isolates could be responsible for resistance to nisin. Field strains of $M$. paratuberculosis were the most sensitive to nisin in both in vitro and in milk cultures. Similar to our results, the effect of nisin on M. tuberculosis and M. kansasii was shown to be dose and time dependent (Carroll et al., 2010). In an earlier study, nisin concentrations up to $1,000 \mathrm{U} / \mathrm{mL}$ did not affect $M$. paratuberculosis viability (Kralik et al., 2018), which is probably related to the genotype of the strain used. Gaggia et al. (2010) indicated that nisin at $2,500 \mathrm{U} / \mathrm{mL}$ had a bactericidal effect on M. paratuberculosis within $30 \mathrm{~min}$. Previously, nisin was shown to be effective against many important spoilage and pathogenic microbes in several dairy products (Sobrino-Lopez and Martín-Belloso, 2006). Milk is the raw material for a variety of dairy prod- ucts, including cheese, butter, cream, yogurt, ice cream, and infant formula. Mycobacterium paratuberculosis has been isolated from raw milk and can survive the process of pasteurization; therefore, $M$. paratuberculosis could be present in dairy products (Grant et al., 2001). Fortunately, nisin at $1,000 \mathrm{U} / \mathrm{mL}$, a dose lower than the permissible dose for nisin treatment of milk for human consumption, was very effective in reducing milk contamination with $M$. paratuberculosis and was effective against both laboratory and clinical isolates.

In this report, we used 2 approaches to better define the mechanism of action of nisin on M. paratuberculosis. First, we used the Live/Dead bacterial viability assay that confirmed the dose-dependent effect of nisin on $M$. paratuberculosis viability by changing the mycobacterial membrane integrity. Previously, nisin was shown to decrease both components of proton motive force in a time- and concentration-dependent manner in $M$. smegmatis and $M$. bovis bacillus Calmette-Guérin (BCG; Chung et al., 2000). It is suggested that nisin, a positively charged peptide, is able to bind to the negatively charged plasma membrane through nonspecific electrostatic interactions. Permeabilization of the cytoplasmic membrane and interference with the cell-wall biosynthesis of sensitive bacteria underlie the antimicrobial activity of nisin (Naghmouchi et al., 2012). To further elucidate the action of nisin on $M$. paratuberculosis, we used scanning electron microscopy, which demonstrated pore formation in the mycobacterial membrane accompanied by significant shape dis- 

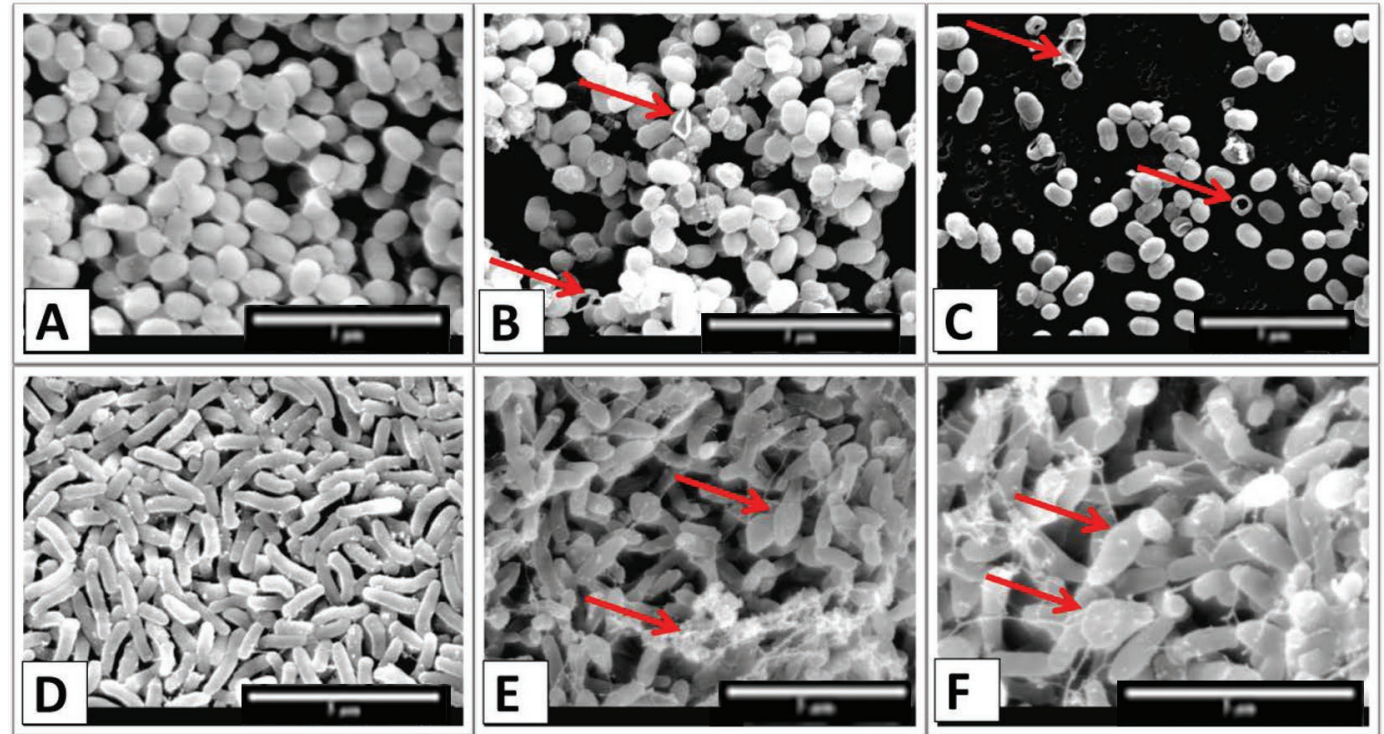

Figure 4. Morphological changes in Mycobacterium avium ssp. paratuberculosis (MAP) following treatment with nisin. Untreated cells of Lactococcus lactis LL108 (A; nisin-sensitive indicator strain) and MAP strain K10 (D; laboratory strain) were intact with regular shape and surface. After treatment with nisin at the MIC, cells appeared misshapen (B, E) with holes in the cell wall (denoted by arrows in B, C). Treated cells of MAP K10 appeared shorter (arrows in E) and bulged (arrows in F) with some ruptured cell walls. All images were captured at a scale of $1 \mathrm{~cm}=5 \mu \mathrm{m}$, except panel $\mathrm{F}$, where $1 \mathrm{~cm}=2.5 \mu \mathrm{m}$.

tortion of bacilli. It is possible that nisin prevents the addition of the lipid II cell wall component (Breukink et al., 2003), which inhibits amino acid transport and affects cytoplasmic membrane integrity, as was shown for Staphylococcus aureus and Bacillus subtilis (Montville et al., 1999). In other words, nisin uses lipid II as a "docking molecule" to form pores on the cell membrane surface in a targeted manner and effectively kill bacteria (Breukink and de Kruijff, 2006), similar to other lantibiotics (Willey and van der Donk, 2007). In $M$. bovis $\mathrm{BCG}$, pores formed by nisin were large enough for export of protons but too small for export of ATP (Chung et al., 2000), whereas in M. smegmatis, the formed pores allowed export of both protons and
A

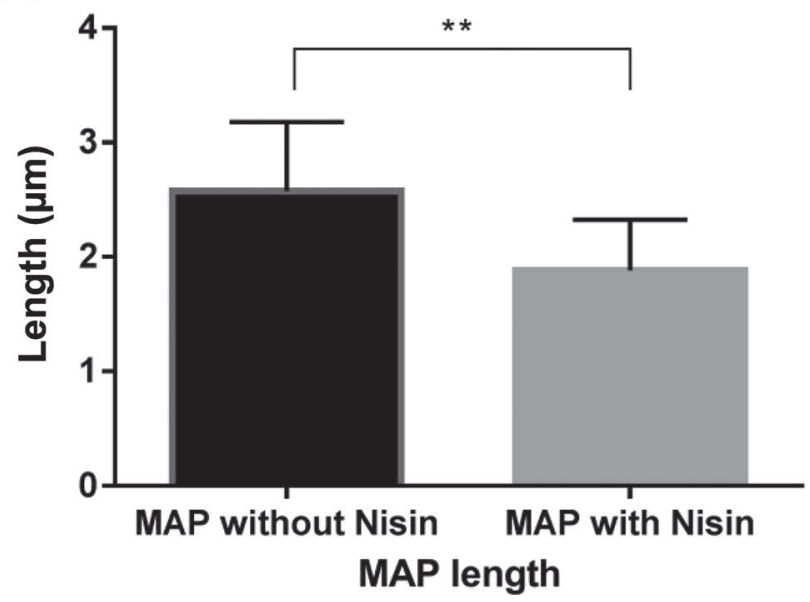

B

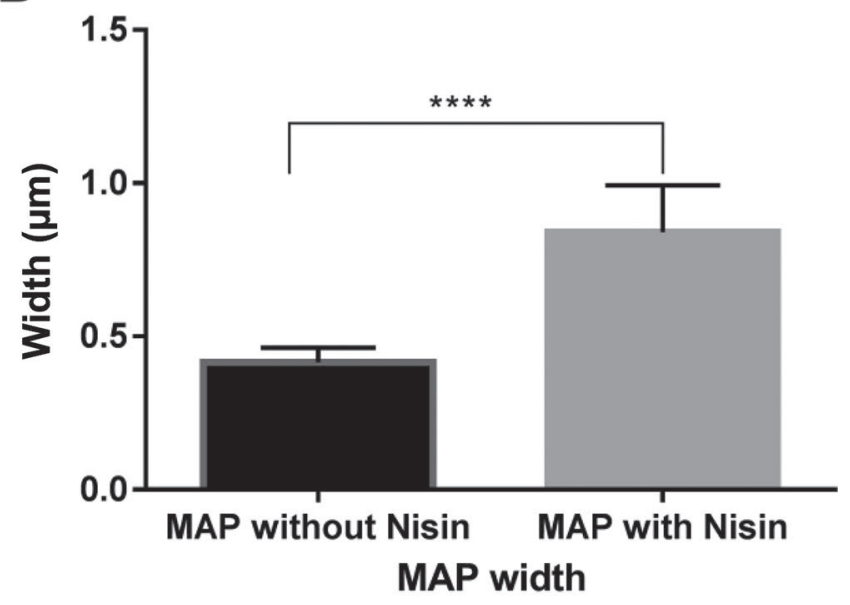

Figure 5. Dimensional differences in mycobacteria bacilli following nisin treatment. Scanning electron micrographs illustrated differences between Mycobacterium avium ssp. paratuberculosis (MAP) K10 bacilli before and after treatment with nisin and dimensional differences were clear. Treated cells were shorter $(1.87 \pm 0.37 \mu \mathrm{m})$ and wider $(0.81 \pm 0.14 \mu \mathrm{m})$ than untreated cells (length: $2.57 \pm 0.60 \mu \mathrm{m}$; width: $0.41 \pm 0.05$ $\mu \mathrm{m})$, resulting in the appearance of bulging. Unpaired $t$-test indicated a significant difference before and after treatment with nisin: $* * * * P<$ $0.0001,{ }^{* *} P=0.0027$. Data represent average of 3 independent replicates plus standard deviation. 
ATP (Montville et al., 1999). More analysis is needed to further characterize the pores formed by nisin treatment of $M$. paratuberculosis. Nonetheless, our analysis indicated the possibility of using nisin to control $M$. paratuberculosis in milk consumed by both animals and humans and improve the microbial quality of feed and food products, respectively.

\section{ACKNOWLEDGMENTS}

The authors thank Emma Hanson for her technical support. This work was partially supported by a USDA grant (NIFA-2018-67015-28243) and Animal formula fund (\#WIS02015) awarded to AT and Egyptian Culture and Educational Bureau to ZA.

\section{REFERENCES}

Altic, L. C., M. T. Rowe, and I. R. Grant. 2007. UV light inactivation of Mycobacterium avium ssp. paratuberculosis in milk as assessed by FASTPlaqueTB phage assay and culture. Appl. Environ. Microbiol. 73:3728-3733.

Balciunas, E. M., F. A. Castillo Martinez, S. D. Todorov, B. D. G. D. M. Franco, A. Converti, and R. P. D. S. Oliveira. 2013. Novel biotechnological applications of bacteriocins: A review. Food Control 32:134-142.

Berger, S., J. P. Bannantine, and J. F. Griffin. 2007. Autoreactive antibodies are present in sheep with Johne's disease and crossreact with Mycobacterium avium ssp. paratuberculosis antigens. Microbes Infect. 9:963-970.

Breukink, E., and B. de Kruijff. 2006. Lipid II as a target for antibiotics. Nat. Rev. Drug Discov. 5:321-332.

Breukink, E., H. E. Van Heusden, P. J. Vollmerhaus, E. Swiezewska, L. Brunner, S. Walker, A. J. Heck, and B. De Kruijff. 2003. Lipid II is an intrinsic component of the pore induced by nisin in bacterial membranes. J. Biol. Chem. 278:19898-19903.

Carroll, J., L. A. Draper, P. M. O'Connor, A. Coffey, C. Hill, R. P. Ross, P. D. Cotter, and J. O'Mahony. 2010. Comparison of the activities of the lantibiotics nisin and lacticin 3147 against clinically significant mycobacteria. Int. J. Antimicrob. Agents 36:132-136.

Chatterjee, C., M. Paul, L. Xie, and W. A. Van Der Donk. 2005. Biosynthesis and mode of action of lantibiotics. Chem. Rev. 105:633684 .

Chiodini, R. J., and J. Hermon-Taylor. 1993. The thermal resistance of Mycobacterium paratuberculosis in raw milk under conditions simulating pasteurization. J. Vet. Diagn. Invest. 5:629-631.

Chung, H. J., T. J. Montville, and M. L. Chikindas. 2000. Nisin depletes ATP and proton motive force in mycobacteria. Lett. Appl. Microbiol. 31:416-420.

Collins, M. T. 1997. Mycobacterium paratuberculosis: A potential foodborne pathogen? J. Dairy Sci. 80:3445-3448.

Cotter, P. D., C. Hill, and R. P. Ross. 2005. Bacteriocins: Developing innate immunity for food. Nat. Rev. Microbiol. 3:777-788.

de Man, J. C., M. Rogosa, and M. E. Sharpe. 1960. A medium for the cultivation of lactobacilli. J. Appl. Bacteriol. 23:130-135.

Delves-Broughton, J., P. Blackburn, R. J. Evans, and J. Hugenholtz. 1996. Applications of the bacteriocin, nisin. Antonie van Leeuwenhoek 69:193-202.

Field, D., M. Begley, P. M. O'Connor, K. M. Daly, F. Hugenholtz, P. D. Cotter, C. Hill, and R. P. Ross. 2012. Bioengineered nisin A derivatives with enhanced activity against both Gram-positive and Gram-negative pathogens. PLoS One 7:e46884.

Franzblau, S. G., R. S. Witzig, J. C. Mclaughlin, P. Torres, G. Madico, A. Hernandez, M. T. Degnan, M. B. Cook, V. K. Quenzer, R. M. Ferguson, and R. H. Gilman. 1998. Rapid, low-technology MIC determination with clinical Mycobacterium tuberculosis isolates by using the microplate Alamar Blue assay. J. Clin. Microbiol. $36: 362-366$.

Gaggia, F., D. S. Nielsen, B. Biavati, and H. Siegumfeldt. 2010. Intracellular $\mathrm{pH}$ of Mycobacterium avium ssp. paratuberculosis following exposure to antimicrobial compounds monitored at the single cell level. Int. J. Food Microbiol. 141(Suppl. 1):S188-S192.

Gao, A., J. Odumeru, M. Raymond, and L. Mutharia. 2005. Development of improved method for isolation of Mycobacterium avium ssp. paratuberculosis from bulk tank milk: effect of age of milk, centrifugation, and decontamination. Can. J. Vet. Res. 69:81-87.

Grant, I. R. 2005. Zoonotic potential of Mycobacterium avium ssp. paratuberculosis: the current position. J. Appl. Microbiol. 98:12821293.

Grant, I. R., H. J. Ball, S. D. Neill, and M. T. Rowe. 1996. Inactivation of Mycobacterium paratuberculosis in cows' milk at pasteurization temperatures. Appl. Environ. Microbiol. 62:631-636.

Grant, I. R., H. J. Ball, and M. T. Rowe. 1998. Effect of high-temperature, short-time (HTST) pasteurization on milk containing low numbers of Mycobacterium paratuberculosis. Lett. Appl. Microbiol. $26: 166-170$.

Grant, I. R., H. J. Ball, and M. T. Rowe. 2002. Incidence of Mycobacterium paratuberculosis in bulk raw and commercially pasteurized cows' milk from approved dairy processing establishments in the United Kingdom. Appl. Environ. Microbiol. 68:2428-2435.

Grant, I. R., A. C. G. Foddai, J. C. Tarrant, B. Kunkel, F. A. Hartmann, S. Mcguirk, C. Hansen, A. M. Talaat, and M. T. Collins. 2017. Viable Mycobacterium avium ssp. paratuberculosis isolated from calf milk replacer. J. Dairy Sci. 100:9723-9735.

Grant, I. R., M. T. Rowe, L. Dundee, and E. Hitchings. 2001. Mycobacterium avium ssp. paratuberculosis: its incidence, heat resistance and detection in milk and dairy products. Int. J. Dairy Technol. 54:2-13.

Grant, I. R., A. G. Williams, M. T. Rowe, and D. D. Muir. 2005. Efficacy of various pasteurization time-temperature conditions in combination with homogenization on inactivation of Mycobacterium avium ssp. paratuberculosis in milk. Appl. Environ. Microbiol. 71:2853-2861.

Hsu, C. Y., C. W. Wu, and A. M. Talaat. 2011. Genome-wide sequence variation among Mycobacterium avium subspecies paratuberculosis isolates: A better understanding of Johne's disease transmission dynamics. Front. Microbiol. 2:236.

Ikonomopoulos, J., I. Pavlik, M. Bartos, P. Svastova, W. Y. Ayele, P. Roubal, J. Lukas, N. Cook, and M. Gazouli. 2005. Detection of Mycobacterium avium ssp. paratuberculosis in retail cheeses from Greece and the Czech Republic. Appl. Environ. Microbiol. 71:8934-8936.

Kralik, P., V. Babak, and R. Dziedzinska. 2014. Repeated cycles of chemical and physical disinfection and their influence on Mycobacterium avium ssp. paratuberculosis viability measured by propidium monoazide F57 quantitative real time PCR. Vet. J. 201:359-364.

Kralik, P., V. Babak, and R. Dziedzinska. 2018. The impact of the antimicrobial compounds produced by lactic acid bacteria on the growth performance of Mycobacterium avium ssp. paratuberculosis. Front. Microbiol. 9:638.

López-Pedemonte, T., I. Sevilla, J. M. Garrido, G. Aduriz, B. Guamis, R. A. Juste, and A. X. Roig-Sagues. 2006. Inactivation of Mycobacterium avium ssp. paratuberculosis in cow milk by means of high hydrostatic pressure at mild temperatures. Appl. Environ. Microbiol. 72:4446.

Lu, Z., Y. H. Schukken, R. L. Smith, R. M. Mitchell, and Y. T. Grohn. 2013. Impact of imperfect Mycobacterium avium ssp. paratuberculosis vaccines in dairy herds: a mathematical modeling approach. Prev. Vet. Med. 108:148-158.

Lubelski, J., R. Rink, R. Khusainov, G. N. Moll, and O. P. Kuipers. 2008. Biosynthesis, immunity, regulation, mode of action and engineering of the model lantibiotic nisin. Cell. Mol. Life Sci. 65:455476.

Meylan, M., D. M. Rings, W. P. Shulaw, J. J. Kowalski, S. BechNielsen, and G. F. Hoffsis. 1996. Survival of Mycobacterium paratuberculosis and preservation of immunoglobulin $\mathrm{G}$ in bovine co- 
lostrum under experimental conditions simulating pasteurization. Am. J. Vet. Res. 57:1580-1585.

Montville, T. J., H. J. Chung, M. L. Chikindas, and Y. Chen. 1999. Nisin A depletes intracellular ATP and acts in bactericidal manner against Mycobacterium smegmatis. Lett. Appl. Microbiol. 28:189193.

Naghmouchi, K., C. Le Lay, J. Baah, and D. Drider. 2012. Antibiotic and antimicrobial peptide combinations: synergistic inhibition of Pseudomonas fluorescens and antibiotic-resistant variants. Res. Microbiol. 163:101-108.

Nauta, M. J., and J. W. van der Giessen. 1998. Human exposure to Mycobacterium paratuberculosis via pasteurised milk: A modelling approach. Vet. Rec. 143:293-296.

Phillips, I., M. Casewell, T. Cox, B. De Groot, C. Friis, R. Jones, C Nightingale, R. Preston, and J. Waddell. 2004. Does the use of antibiotics in food animals pose a risk to human health? A critical review of published data. J. Antimicrob. Chemother. 53:28-52.

Rilla, N., B. Martinez, T. Delgado, and A. Rodriguez. 2003. Inhibition of Clostridium tyrobutyricum in Vidiago cheese by Lactococcus lactis ssp. lactis IPLA 729, a nisin Z producer. Int. J. Food Microbiol. $85: 23-33$

Rilla, N., B. Martinez, and A. Rodriguez. 2004. Inhibition of a methicillin-resistant Staphylococcus aureus strain in Afuega'l Pitu cheese by the nisin Z-producing strain Lactococcus lactis ssp. lactis IPLA 729. J. Food Prot. 67:928-933.

Rowan, N. J., S. J. Macgregor, J. G. Anderson, D. Cameron, and O. Farish. 2001. Inactivation of Mycobacterium paratuberculosis by pulsed electric fields. Appl. Environ. Microbiol. 67:2833.

Singh, M., and K. Mukhopadhyay. 2011. C-terminal amino acids of alpha-melanocyte-stimulating hormone are requisite for its antibac- terial activity against Staphylococcus aureus. Antimicrob. Agents Chemother. 55:1920-1929.

Slana, I., P. Kralik, A. Kralova, and I. Pavlik. 2008. On-farm spread of Mycobacterium avium ssp. paratuberculosis in raw milk studied by IS900 and F57 competitive real time quantitative PCR and culture examination. Int. J. Food Microbiol. 128:250-257.

Sobrino-López, A., and O. Martín-Belloso. 2008. Use of nisin and other bacteriocins for preservation of dairy products. Int. Dairy J. 18:329-343.

Sobrino-López, A., and O. Martín-Belloso. 2006. Enhancing inactivation of Staphylococcus aureus in skim milk by combining highintensity pulsed electric fields and nisin. J. Food Prot. 69:345-353.

Sweeney, R. W., R. H. Whitlock, and A. E. Rosenberger. 1992. Mycobacterium paratuberculosis cultured from milk and supramammary lymph nodes of infected asymptomatic cows. J. Clin. Microbiol. $30: 166$.

WHO (World Health Organization). 2001. Pre-harvest food safety. Report of a WHO consultation with the participation of the Food and Agriculture Organization of the United Nations and the Office International des Epizooties. WHO/CDS/CSR/EPH/2002.9. WHO, Geneva, Switzerland.

Willey, J. M., and W. A. van der Donk. 2007. Lantibiotics: Peptides of diverse structure and function. Annu. Rev. Microbiol. 61:477-501.

Wong, S. Y., I. R. Grant, M. Friedman, C. T. Elliott, and C. Situ 2008. Antibacterial activities of naturally occurring compounds against Mycobacterium avium ssp. paratuberculosis. Appl. Environ. Microbiol. 74:5986-5990.

Wu, C. W., S. K. Schmoller, S. J. Shin, and A. M. Talaat. 2007. Defining the stressome of Mycobacterium avium ssp. paratuberculosis in vitro and in naturally infected cows. J. Bacteriol. 189:7877-7886. 